PRINT ISSN 1119-8362

Electronic ISSN 1119-8362
Full-text Available Online at

https://www.ajol.info/index.php/jasem

http://ww.bioline.org.br/ja
J. Appl. Sci. Environ. Manage.

Vol. 24 (9) 1523-1527 September 2020

\title{
Food Waste Bioeconomy: Sustainable Waste Management Options for Hawassa University Campuses, Ethiopia
}

\author{
ABATE FEYISSA SENBETA \\ Department of Biology, College of Natural and Computational Sciences, Hawassa University, P. O. Box, 05, Hawassa, Ethiopia \\ Email:abatefs@yahoo.com,Tel: +251-910283502
}

\begin{abstract}
Food waste management is a challenge in University Campuses of developing countries. This study assessed food waste management challenges in Hawassa University and the possibility of cascading the waste through biomass bioeconomy model by using interviews, observations and published and unpublished documents. The results show that so far the food leftover is being used by poor people, collected by animal ranchers or damped in an openpit. Food leftover use by poor people was challenged due to poor hygienic quality, health implication to users, insecurity to campus community and theft of property in the campuses. The university's animal enterprise was also forced to quiet its agreement with the university due people's competition for the leftover. Generally food waste management at the University is reactive and long-term sustainability is needed. This study suggests the cascading use of biomass, i.e. using food waste as animal feed; animal waste as feedstock for biogas generation; biogas-slurry as an organic fertilizer for university farm and plantations. If implemented the model improves the waste management practices of the University; improves the resource use efficiency and energy security, and reduces fuel wood consumption and mitigate greenhouse gas emission. Moreover the model creates circular economy that serves as a sustainability showcase in practice for research, training, recreation, experience sharing and income generation activities.
\end{abstract}

\section{DOI: https://dx.doi.org/10.4314/jasem.v24i9.6}

Copyright: Copyright $(2020$ Abate. This is an open access article distributed under the Creative Commons Attribution License (CCL), which permits unrestricted use, distribution, and reproduction in any medium, provided the original work is properly cited.

Dates: Received: 25 August 2020; Revised: 25 September 2020; Accepted: 20 September 2020

Keywords Bio-economy, food waste, Hawassa University, sustainability

Waste is defined as 'abandoned-materials' that are discarded as to no longer have a functional use, or economic-value (Starovoytova, 2018; Zaman \& Lehmann, 2011). The solid waste management (SWM) treats all solid materials as a single class. However, solid waste is a heterogeneous-material, vary in terms of composition, volume and based on the prevailing activities and the demography of individuals at the source (Coker et al., 2016; Williams, 2005). Comprehensive SWM is one of the greatest challenges in bringing institutional sustainability (Smyth et al., 2010). In principle solid waste management involves preventing and/or minimizing waste generation, segregation of waste by type at the source; employing recycling, reuse and resource recovery, and ensuring the safe and environmentally sound disposal (de Vega et al., 2008; Jansen, 2010). In developing countries significant portion of population does not have access to a waste collection service and only a fraction of the generated waste is actually collected. Most of the solid waste is disposed in open dumps due to its simplicity and low cost (Nas \& Bayram, 2008; WHO, 1996).

Solid waste management is generally a major problem in Ethiopia (Cheever, 2011) and it has become a priority issue in higher institutions. Though the higher education system in Ethiopia has begun in the mid1960 s, the country's higher education system has expanded remarkably in recent years. The annual average student enrolment rate in public and private higher institutions between 2003/04 and 2016/17 has increased by $26.1 \%(58,632$ to 860,378$)$ (EMIS, 2016/2017). The expansion of programs and rise in student and staff number has undoubtedly increased the solid waste generated from the institutions. Consequently solid waste management in higher education institutions in Ethiopia has become one of the greatest challenges for institutional sustainability (Helelo et al., 2019; Kassaye, 2018; Mengesha and Dessalegn, 2014; Seyoum, 2007).

Food production requires many resources, and is responsible for a significant portion of the greenhouse gas (GHG) emissions. Food wastes are typically one of the heaviest components of an organic waste stream, and thereby transporting food wastes to distant a site results in additional emissions and extra resources use (FAO, 2013). Therefore, reducing foodlosses and diverting food waste into usable products through circular bio-economy model at all stages can play role in solving various social and environmental 
problems, including pollutions, the spread of diseases and the release of greenhouse gases. In Ethiopia several achievements were reported including reclamation of degrade lands into fertile grounds, and urban agriculture (e.g. seedlings, vegetables and small animals) through use of organic wastes. However, solid waste based bio-economy potential of the country is unknown. Therefore the objective of this paper is to identify the major challenges of Hawassa University campus food leftover management and possibility of cascading its use through bioeconomy model.

\section{MATERIALS AND METHODS}

Study area description: The study was conducted in Hawassa University, one of an officially accredited and recognized higher institution in Ethiopia. Currently it has 7 campuses: Main Campus, Technology Campus, Wondogenet Campus, Health Campus, Agriculture Campus, Awada Campus and Bensa Daye Campus. All the campuses except Wondogenet, Awada and Bensa Daye are located in Hawassa City. According to the University Registrar and Alumni affairs directorate information the total number of student population in 2019 was 41,929. From the programs $58 \%$ of the students are in regular program, $22.6 \%$ are in summer program and the remaining is in an evening and weekend programs. The total employed permanent staff workers excluding Bensa Daye campus was 8604. The number of cleaners in Main Campus was 268 (111 permanent, 139 temporary and 18 office workers).

Table 1: Number of student and staff in the seven campuses of HU in 2018/2019 academic year

\begin{tabular}{lcccc}
\hline Name of campus & $\begin{array}{c}\text { Regular } \\
\text { students }\end{array}$ & $\begin{array}{c}\text { Weekend } \\
\text { students }\end{array}$ & $\begin{array}{c}\text { Evening } \\
\text { students }\end{array}$ & $\begin{array}{c}\text { Summer } \\
\text { students }\end{array}$ \\
\hline Main Campus & 6242 & 2976 & 4441 & 7706 \\
Wondogenet Campus & 2279 & 262 & 0 & 361 \\
Health Campus & 2807 & 73 & 90 & 0 \\
Agriculture Campus & 2333 & 172 & 0 & 430 \\
Awada Campus & 2576 & 0 & 0 & 0 \\
Technology Campus & 7512 & 435 & 578 & 827 \\
Daye Campus & 329 & 0 & 0 & 0 \\
Total & $\mathbf{2 4 0 8 9}$ & $\mathbf{3 9 1 8}$ & $\mathbf{5 1 0 9}$ & $\mathbf{9 3 2 4}$ \\
\hline
\end{tabular}

Data collection and analysis: In the present study preliminary survey was carried out in HU campuses, and all the possible food leftover sources were identified. Key informant interview was held with people close to food waste management and working at different positions of the university (e.g. cafeteria managers, leaders of dormitory, University Hotel, student dean, director of animal farm). The key informants are closer to solid waste management and are believed to have detailed know-how on the past, present and future plan of the university on food leftover management. The questions include amount generated, practices on food leftover management such as source reduction, recycling or reuse of food leftover wastes, and current practice of waste storage, collection, transportation and disposal. The major challenges of food waste use for poor people, animal feed or energy recovery was also examined during the interviews. Participant observation was conducted to collect firsthand information on food waste management practices starting from source to the final disposal. The information was organized and summarized quantitatively and qualitatively.

\section{RESULTS AND DISCUSSION}

Sources of food waste and current management practices: The major sources of food waste in Hawassa University are student cafeteria, teaching hotel, lounges, staff residence and conference halls. The type and amount of food leftover varies depending on the source. Food waste from cafeteria (peels and food leftover) comprises the largest share of food waste and other solid waste at large which is followed by animal waste (animal dung and poultry manure) and paper waste. The initial practice of food leftover waste management in the University involves collection of waste from the point of generation and disposal through open surface dumping. Damping food waste caused foul smells, bad scenery, attracted scavenger birds, flies and other pests to the site. The offensive odor, sanitation problem and environmental pollution (soil, water and air) were particularly aggravated during rainy seasons, and it became a potential health concern for the university community. Waste heaps, dumps and land fill obviously emitted a potent greenhouse gases such as $\mathrm{CH}_{4}$ and $\mathrm{N}_{2} \mathrm{O}$, and releases considerable quantities of liquid leachate to the ground water. Latter the university entered into an agreement with pig ranchers to collect a food waste from student cafeteria. The food leftover food from student cafeteria was being sold for 16,000 Ethiopian birr/month in Main Campus and 7500 birr/month in Health Campus in 2013/2014 (1\$ = 19.128 birr $)$. However, the bule (food leftover) said to be used to feed pig was actually sold to needy people in the city. Finally the university quitted the agreement with the 
rancher after confirming its sell to poor people in the city. The food is a mix of leftover cleaned from dining tables and transported in unhygienic sack/barrel which could be a potential health risk (Main Campus Student Dean, 2019). In 2018 the university enterprise officially started using food waste for beef and dairy cattle. The leftover was properly dried before use to ensure the feed quality on the animal's health. Yet the bule intended for the enterprise animals attracted several competitors, children and daily laborers. Yet most of the peels and unused food waste is open damped (Figure 1). Similarly animal waste from dairy farm was managed by flashing it into an open-pit (Figure 2). A small portion of animal waste was used as fertilizer for campus plantation and animal farm.

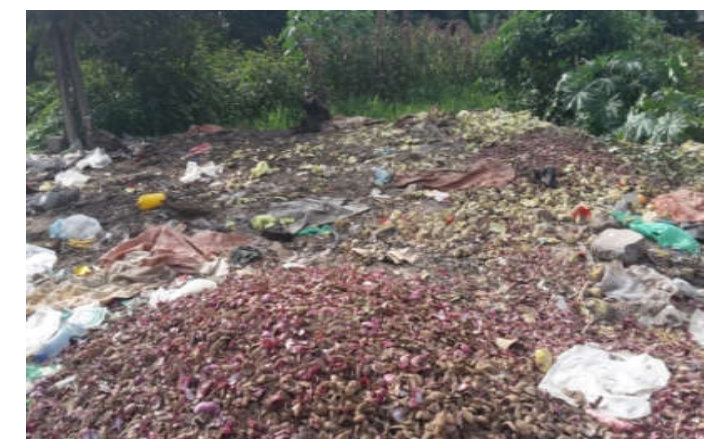

Fig 1: Open damping of food waste in Agriculture Campus of HU

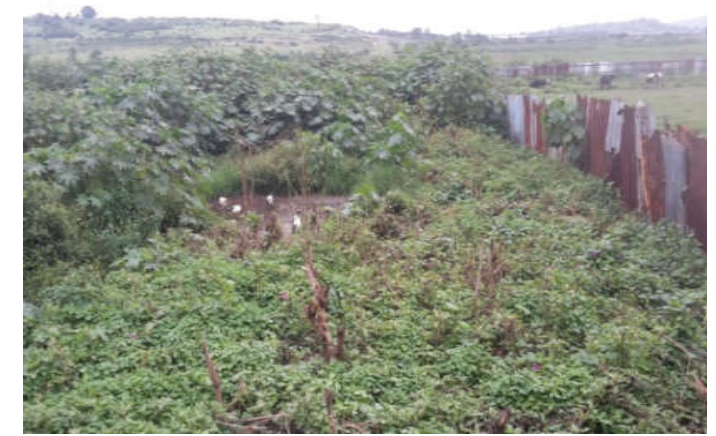

Fig 2: Animal waste flushing into open-pit at HU Main Campus

Challenges of food waste management in Hawassa University: Several food waste management strategies were tried but it lacks the desired goal, and the institution is looking for more proactive, safe and effective mechanism to handle the solid waste. The solid waste management proclamation No. 513/2007 obliges the university administrations to plan, collect and store, transport and dispose/landfill solid wastes. Article on food related wastes (Article 10) articulates that "food industries and restaurants shall collect, store, and dispose of the food related solid wastes they generate in an environmentally sound manner." Therefore the University is answerable for improper SWM and the institution has a mandate to segregation, ensuring placement of waste collection facilities in place, prohibiting of waste disposal at public places and ensuring environmentally sound disposal sites. According to the waste hierarchy (Figure 3) food waste prevention activities are most preferred, and followed by reuse activities and recycling (Imbert, 2017). Though waste prevention is most preferred sustainable solution it is considered as the most challenging waste management strategy (Imbert, 2017; Papargyropoulou et al., 2014; Yolin, 2015). In Hawassa University the organic waste prevention can be achieved at limited points in the food cycle value chain. Improving the quality of raw material purchased, reducing wastage at storage, using improved peeling technology, improving quality prepared food and using sustainable waste management strategy are important points needed to reduce waste generation. According to one informant "the amount of food leftover is higher on days when cabbage is served as part of daily menu in student cafeteria because many students prefer missing and eating from other places".

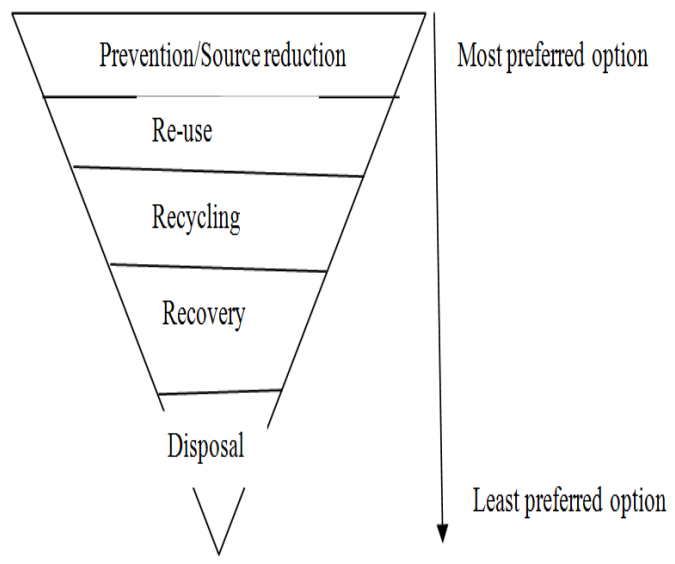

Fig 3: Solid Waste Management Hierarchy Policy Options. Adopted from http://ec.europa.eu/environment/waste/framework/

Food leftover donation to the poor: Food leftover donation to poor of the poor (tesfegnoch) is a preferred management strategy next to source reduction when compared to feeding to animals, energy recovery, composting or land-filling. Feeding food leftover for tesfegnoch is a re-use form of waste management option if the health quality of the food is ensured. Food sharing/donation to needy people was also encouraged by organizations such as the European Union (EC, 2017). However, besides the safety problem of food leftover generated the operational and legality of leftover redistribution at Hawassa University can be questioned due to problems being created by the users. The attraction of people to the University for Food leftover has created fight for the food, increased 
insecurity of students and cafeteria workers, theft of property and damage to campus plantation. Moreover according to one of the Main Campus Cafeteria Manager 'giving food leftover to tesfegnoch creates dependency syndrome on leftover users, and increases user children school absenteeism and drop-outs'. ' 'The people coming for food leftover during morning and evening are trampling farm plants" (keyinformant from animal farm). Moreover, in-the-localcontext food leftover is socially and culturally unacceptable and lowers user families' prestige.

Food waste as animal feed: In the main campus, the university has established plant farm, aquaculture, animal farm (dairy, beef and poultry) and abattoir services. The demand for agricultural products within and outside the university is increasing, and the university enterprise has a plan to invest on expansion and diversification of the farm system and its modernization. The idea of establishing botanical garden in the main campus is also underway but stacked at mapping stage due to financial constraint. The Main Campus and Technology Campuses are nearby each other and, therefore, the organic waste from both campuses can be managed through integrated circular bio-economy model as shown in Figure 4.

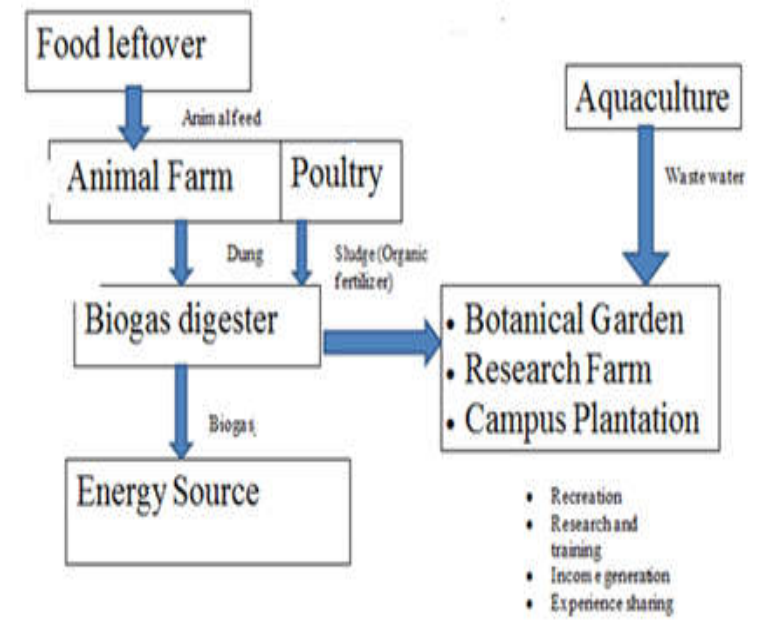

Fig 4: Suggested integrated bio-economy model for Organic SWM in Hawassa University Main and Technology Campuses.

The Hawassa University enterprise has already started recycling food waste as animal feed since 2018 , but the practice did not last for long due competition of poor people with animals. According to an informant from animal farm "so far the university has no consistent stand on food leftover management; it should choose to donate the leftover to poor people or to the enterprise as a feed. If it is aimed for the enterprise animals the food waste must be collected properly in a hygienic way and the interference of poor people must be stopped." From sustainability point of view using food waste as animal feed reduces the energy, water, fertilizer and other resources needed to grow crops and transport feed. The animal waste from dairy farm is currently connected to septic tank system that discharged waste into an open-pit, which contributes to human induced emissions of gases including methane, ammonia and nitrous oxide (Caro et al., 2014), http://www.fao.org/3/a-a0261e.pdf). Using animal waste (dung and poultry dropping) as feedstock to produce combustible methane gas for cooking and lighting reduces emission of GHGs from land-filling (Ojolo et al., 2007). The wasted part of the food leftover can be mixed with animal dung and poultry manure as feedstock for biogas digester to increase the efficiency of biogas generation (Chibueze et al., 2017; Muthu et al., 2017). According to the data obtained from the University student service directorate office, besides electricity the main campus uses about $19.95 \mathrm{~m}^{3}$ woods per day for cooking in student cafeteria which costs Et Birr 11,471.25 per day in 2014. In addition to electricity the yearly firewood consumption in main campus student cafeterias alone was $1900 \mathrm{~m}^{3}$ in $2017 / 2018$ and the planned consumption for $2018 / 2019$ was $2800 \mathrm{~m}^{3}$. The university depends on the fire wood due to unreliability and inadequacy of power supply. The biogas use fills the energy gap created by power interruptions and replaces the firewood consumption at least in some of the cafeteria. The bioslurry, byproduct from biogas plant, can be used as an excellent biofertilizer to improve soil physical, chemical, and biological property. The use of biogas and bioslurry as electricity and fertilizer respectively in countries such as Ethiopia is reduces the burden on ruminant forests, reliance on chemical fertilizer and emission of greenhouse gases, and it is consistent with the ideas that are inherent in climate smart agriculture and sustainable development.

Conclusions: The food waste management in Hawassa University has been reactive. If implemented the food waste based integrated bio-economy model reduces the socioeconomic and environmental problems associated with the waste. In the model the food waste is used as animal feed, and the animal waste is used to produce biogas and the bioslurry from biogas plant is used for campus plantation. The implementation of the model improves SWM of the campus, and will serve as a sustainability showcase in practice for research, training and experience sharing.

\section{REFERENCES}

Caro D; Davis SJ; Bastianoni S \& Caldeira K (2014).

Global and regional trends in greenhouse gas emissions from livestock. Climatic Change, 126 (1-2), 203-216. 
Cheever M (2011). Waste Management in Ethiopia. Environmental Policy Review.

Chibueze U; Okorie N; Oriaku O; Isu J \& Peters E (2017). The Production of Biogas Using Cow Dung and Food Waste. Inter. J. Mat. Chem. 7 (2), 21-24.

Coker A; Achi C; Sridhar M \& Donnett C (2016). Solid Waste Management Practices at a Private Institution of Higher Learning in Nigeria. Procedia Environ. Sci. 35, 28-39.

de Vega CA; Benítez SO \& Barreto MER (2008). Solid waste characterization and recycling potential for a university campus. Waste Manage. 28, S21-S26.

EC (2017). Report from the Commission to the European Parliament, the Council, the European Economic and Social Committee and the Committee of the Regions. Strategic report 2017 on the implementation of the European Structural and Investment Funds.

EMIS. (2016/2017). Education Statistics Annual Abstracts Addis Ababa: Ministry of Education, Federal Democratic of Ethiopia.

FAO (2013). Food Wastage Footprint: Impacts on Natural Resources: Summary Report: FAO.

Helelo A; Senbeta A \& Anshebo S (2019). Assessment of Solid Waste Management (SWM) Practices in Hawassa University Campuses, Ethiopia. J. Appl. Sci. Environ. Manage., 23 (6), 1081-1086.

Imbert E (2017). Food waste valorization options: opportunities from the bioeconomy. Open Agriculture, 2 (1), 195-204.

Jansen JlC (2010). Anaerobic digestion: technology. Solid Waste Tech. Manage. 1, 601-617.

Kassaye AY (2018). Contemporary institutional solid waste management practices of Haramaya University, Eastern Ethiopia. Afr. J. Sci. Tech. Innovate. Develop. 10 (2), 219-238.

Mengesha HB \& Dessalegn BY (2014). Solid waste Characterization and Recycling Potential in Hawassa University, Ethiopia. Inter. J. Environ. Ecol. Eng. 8 (2), 74-76.

Muthu D; Venkatasubramanian C; Ramakrishnan K \& Sasidhar J (2017). Production of Biogas from wastes Blended with CowDung for Electricity generation-A Case study. Paper presented at the IOP Conference Series: Earth and Environmental Science.

Nas SS \& Bayram A (2008). Municipal solid waste characteristics and management in Gümüşhane, Turkey. Waste management, 28 (12), 2435-2442.

Ojolo S; Oke S; Animasahun K \& Adesuyi B (2007). Utilization of poultry, cow and kitchen wastes for biogas production: A comparative analysis. $J$. Environ. Health Sci. Eng., 4 (4), 223-228.

Papargyropoulou E; Lozano R; Steinberger JK; Wright N \& bin Ujang Z (2014). The food waste hierarchy as a framework for the management of food surplus and food waste. J. Clean. Product. $76,106-115$.

Seyoum K (2007). Study on municipal solid waste management of Addis ababa university. Addis Ababauniversity.

Smyth DP; Fredeen AL \& Booth AL (2010). Reducing solid waste in higher education: The first step towards 'greening'a university campus. Resources, Conserve. Recycl. 54 (11), 1007-1016.

Starovoytova D (2018). Solid Waste Management (SWM) at a University Campus (Part 1/10): Comprehensive-Review on Legal Framework and Background to Waste Management, at a Global Context. J. Environ. Earth Sci. 2225-0948.

WHO (1996). Guides for municipal solid waste management in Pacific Island countries: Kuala Lumpur: WHO Western Pacific Regional Environmental Health Centre.

Williams PT (2005). Waste treatment and disposal: John Wiley \& Sons.

Yolin C (2015). Waste management and recycling in Japan opportunities for European companies (SMEs focus). EU-Japan Center for Industrial Cooperation: Tokyo, Japan.

Zaman AU \& Lehmann S (2011). Urban growth and waste management optimization towards 'zero waste city'. City, Culture and Society, 2 (4), 177187. 